\title{
The Drivers of Academic Success for 'Bright' but Disadvantaged Students: A Longitudinal study of AS and A-Level Outcomes in England
}

\author{
Introduction
}

Economic and educational inequalities continue to hinder social mobility and decrease the chances of disadvantaged children achieving the same levels of academic success as their more advantaged peers and there is growing international concern about the effects of disadvantage in shaping life chances and affecting economic performance (Causa \& Chapins, 2009; Causa \& Johansson, 2010). There is evidence that the effects of disadvantage are cumulative such that the equity gap increases as children grow older, especially during secondary schooling (Sammons, 2010; Sutton Trust, 2011; Ermisch, 2012; Crawford, Macmilllan \& Vignoles, 2017). International comparisons reveal variation between countries in the size of the equity gap, typically it is larger in English speaking countries including the US, England (and the UK constituent countries) Australia and New Zealand, although not in Canada, and also larger in countries with earlier selection or tracking of students (OECD, 2013). In England, past research (Sutton Trust, 2004; 2005) shows that social and financial disadvantage reduces young people's later attainment in public examinations post 16 especially for Advanced-level qualifications taken at ages 17/18 years. The first part of Advanced level study is known as the Advanced Subsidiary level (AS level). The second part is known as the A2 Level. The AS Level is a qualification in its own right, and the AS Level together with the A2 Level forms the complete A-Level qualification. Advanced level qualifications are needed as entry requirements for enrolment to most higher education (HE) courses in England. In addition to differences in Advanced level results associated with family social disadvantage, measured by parents' socio-economic status (SES) or income, there is evidence of neighbourhood effects linked to 'place' poverty in England. Young people living in the most disadvantaged areas are nearly three times less likely to participate in higher education than their peers living in more advantaged neighbourhoods, whereas the most advantaged young people are seven times more likely to attend prestigious universities than the most disadvantaged (Social Mobility and Child Poverty Commission, 2013).

\section{Educational Effectiveness Research}

Various individual child, family, and neighbourhood characteristics are known to be significant predictors of children's academic and social-behaviour outcomes and contribute to the equity gap in achievement. For this reason, it is important in educational effectiveness research (EER) studies to control for differences between schools or classes in student 
intake differences to evaluate the effects of schools (Mortimore et al., 1994; Gustaffson, Hansen, \& Rosen, 2011; Muijs \& Reynolds, 2003; Sammons, 1995; Sammons, Davies, \& Gray, 2016; Scheerens and Bosker, 1997; Strand, 2014a \& b). Jackson and colleagues (2007) point to the existence of both primary and secondary effects of background. 'Primary' effects are associations between attainment and background, while 'secondary effects' are argued to be those linked to student or system 'choices' that may further reinforce inequalities in outcomes. In the research that is the focus of this paper such 'choices' would include staying on in education to enter Advanced level qualifications necessary for subsequent HE entry after the end of compulsory schooling (age 16 for the sample in this research).

EER has made important theoretical contributions to understanding the role of schools in shaping variations in students' educational outcomes (Scheerens and Bosker, 1997; Creemers and Kyriakides, 2008; Creemers, Kyriakides \& Sammons, 2010; Scheerens, 2015). It has been demonstrated that school effectiveness matters more for disadvantaged groups because they are at greater risk of poor attainment and also that school effects tend to be larger for disadvantaged students (Scheerens \& Bosker, 1997). This points to the importance of studying differential effects for particular student sub-groups (Creemers, Kyriakides and Sammons, 2010). Kyriakides and Creemers (2011) go further by investigating two dimensions of effectiveness, both quality and equity. Applying the 'fairness principle' they argue that equity implies differences in student outcomes should not be primarily attributable to factors such as gender, family wealth, income or power. The equity effectiveness of schools is thus measured by how far they exacerbate or, by contrast, reduce differences in student outcomes attributable to such background influences. The quality dimension relates to schools' relative 'value added' performance in raising student results overall. Taken together Kyriakides and Creemers (2011) show that schools can be classified in terms of these two dimensions, with high quality and high equity taken together as a way to establish overall effectiveness. They argue that further research is needed to establish which features of schools and teaching can help to promote effectiveness in terms of both equity and quality.

EER studies of school and teacher effectiveness have demonstrated that teacher (or classroom) effects are typically larger than those attributable to schools (Reynolds et al, 2014; Muijs et al., 2014). Nonetheless, the multilevel nature of school and teacher influences is recognised in EER theoretical models. Thus while teachers' classroom influences may be more influential in promoting students' learning outcomes, schools also play a role by shaping the context in which teachers' work and the organizational culture. School influences are more typically indirect while those of teachers more likely to be direct according to such theoretical models (Scheerens \& Bosker, 1997; Creemers \& Kyriakides, 2008; Reynolds et al., 2014). Muijs et al. (2014) provide an authoritative 'state of the art' review of teacher and classroom influences on student learning outcomes. This highlights concepts such as 'Opportunity to learn and time on task', Instruction and interaction (including questioning and feedback), Classroom climate and 'Teacher expectations'.

Most previous research into students' continued participation in HE has not adopted an EER perspective. In England, it has focused on the immediate requirements students need for higher education entry by studying differences in students' General Certificate of Education (GCSE) public examination results at age 16, or in A-level results at age 18 for different 
student groups. However, in order to better understand the interconnections between family background, academic attainment, educational experiences and the likelihood of obtaining results that enable admission into $\mathrm{HE}$, it is necessary to follow children's experiences and academic attainment longitudinally across different phases of education as they move through primary and secondary schooling. Individual, family and both home and school learning experiences (including those related to teaching) can vary in influence at different educational stages. Some may have longer term effects, others perhaps are only influential at particular time points. Identifying these different influences will increase understanding of the main drivers of the equity gap over time and suggest the most fruitful foci for school improvement and evaluations of policy interventions intended to promote greater equity in access to HE.

Crawford, Macmillan and Vignoles (2017) provided an important recent contribution studying educational trajectories in England focusing on different student groups divided by high, average or low attainment at age 7 . However, their large scale study based on national data sets was limited by reliance on a limited set of demographic variables and only followed children up to age 16 using GCSE results in public examinations. It did not track students into post 16 Advanced level study. Due to data limitations inherent in only using national data sets, the Crawford, Macmillan and Vignoles (2017) study could not explore the potential role of pre-school, primary or secondary school processes nor the effects of children's home learning environments.

\section{Home learning environments}

There is growing interest in the role of children's home learning environments in supporting better child outcomes in schooling. Its role is well documented for infants' development (Bradley, 1994), and early childhood intellectual competencies (Bradley \& Caldwell, 1982). In addition, studies have explored its effects on early literacy and numeracy outcomes (Anders et al., 2012; Melhuish et al., 2008; Van Steensel, 2006). Moreover, research suggests the home learning environment can interact with pre-school and primary school processes in shaping children's achievement trajectories (Sammons et al., 2008a and 2008b). Nonetheless, there is little longitudinal research that explores the effects of the home learning environment across different phases of education and at different ages (Sammons et al, 2015) and as yet its contribution to later attainment outcomes that are required for $\mathrm{HE}$ entry has not been explored.

\section{A Longitudinal Cross Phase Study of the Predictors of Students' Advanced-level Attainment Outcomes in England}

Few studies have investigated children's attainment and progress from earlier phases of education until entry to higher education by simultaneously examining the influences of child and family background, neighbourhood characteristics and educational experiences within a longitudinal design (Chowdry et al., 2013). This article addresses this deficit. It provides a longitudinal perspective on equity differences in children's attainment outcomes across different phases of education in England. In contrast to much previous educational research with an equity focus, it seeks to highlight factors that help disadvantaged children to succeed as they move through different phases of education, not just those that put such children at greater risk of poor outcomes. After identifying a group of high attaining disadvantaged 
children at age 11 it then follows this group up to age 18 to see whether they continue to experience relative academic success or fall behind similarly high attaining but less disadvantaged peers. The study seeks to inform approaches to the evaluation of equity in education and the development of foci for future interventions.

Aims

The research aims to illuminate the 'drivers' of success for disadvantaged children by:

1) analysing the later AS/A-level attainment of 'bright' children (a shorthand to classify those children identified in primary school who achieved above average results at Level $5+$ in national assessments taken at age 11 years) from disadvantaged families as they moved through secondary education and comparing their outcomes to those of other 'bright' children (above average attainers at age 11) who were more advantaged;

2) exploring the characteristics of students who gained 'good enough' A-level qualifications for university entrance at ages 17/18 years and identifying barriers or facilitators for obtaining good AS/A-level results for the most disadvantaged students;

3) establishing what educational experiences enhance or reduce the later academic success of such 'bright' but disadvantaged students in secondary school.

This research draws on the EER knowledge base and methodological approaches. It adopted an ecological perspective (Bronfenbrenner, 1989) in modelling potential influences on AS/A-level success. This first identified child and family influences (that can be viewed as more 'proximal to the child, including the home learning environment), before testing other features of educational experiences from pre-school, then primary and later secondary school.

\section{Sample and Methods}

The sample for this research is drawn from the Effective Pre-school, Primary and Secondary Education Project (EPPSE3+-16), a longitudinal study of the progress and development of children from pre-school through to post-compulsory education in England (Sammons et al., 2005; 2008a; 2008b; 2012; 2013; 2014a \& b; Sylva et al., 2010; 2014). EPPSE recruited a a stratified random sample of children and families drawn from 141 pre-schools in six regions from five types of provider. EPPSE has investigated various aspects of pre-school, primary and secondary school provision that shape children's attainment, progress and development over successive phases of education up to age 16 and informed education policy development in the early years (Siraj-Blatchford et al., 2008; Taggart et al., 2008).

The EPPSE sample of 3172 children was assessed at the start of pre-school, when children turned three years old and their development was monitored until they entered primary school (mean age 4 years 9 months). It also included over 300 'home' children who had not attended any type of pre-school recruited to the study at age five from reception classes attended by children in the original EPPSE pre-school sample. They provided a comparison 'no pre-school' group of children drawn from the same neighbourhoods and schools as the pre-school sample. The full EPPSE sample was then followed up across primary school into adolescence with children assessed at ages $6,7,10,11,14$, and 16 until the end of 
compulsory secondary schooling. The overall EPPSE sample was found to be broadly representative of the characteristics of children in England nationally based on comparisons with national Department for Education (DfE) statistics on key measures including Free School Meals (FSM) status, lone parent status and ethnicity (Sylva et al., 2010). It should be noted that the 'no-pre-school' group were more disadvantaged than the pre-school group (again this was found to be in line with the national pattern in England) but it included sufficient overlap for robust statistical comparisons of outcomes between the pre-school and no-preschool groups (Cattan, Crawford and Dearden, 2014; Hall et al., 2013; Sammons et al., 2002, 2008a and b, 2008b; 2014; Sylva et al., 2010).

A Sutton Trust funded follow-up study (Sammons, Toth and Sylva, 2015a, 2015b) investigated EPPSE students' destinations (academic/non-academic routes) post 16, their AS and A-level take up in public examinations and attainment in these examinations in Key Stage 5 (ages17/18 years). Data was provided from the DfE's National Pupil Database (NPD) and included number of AS and A-levels entered and number attained, subjects taken, examination grades and total AS and A-level point scores. These new attainment measures were merged with the main EPPSE dataset that included a wide range of information on child, family and neighbourhood characteristics and measures of primary and secondary schools collected at earlier time points. A particular focus was to identify and then track outcomes for a 'bright' but disadvantaged group.

\section{Measures}

The EPPSE dataset provided a range of information on these young people's lives and educational/social progress from the early years at age 3 to age 16+. Information was collected from parents at entry to the study by semi-structured interviews. Questionnaires were administered to students (at ages 7, 10, and 14). Various assessments of students' academic, social and attitudinal development were also collected across 8 time points (Sylva et al, 2010; 2014).

\section{Home learning environment (HLE)}

All parents were interviewed using a semi structured schedule to collect a range of information about the children, their families and various activities at home recruitment to study (response rate over 97\%, (Sylva et al, 2010). The early years HLE measure was based on parents' reports of the frequency of their engagement in activities and interactions with their child such as going to the library, being read to, learning about the alphabet and numbers/shapes, songs/poems/nursery rhymes and painting or drawing activities when children were recruited to the EPPSE study. The frequency of each of seven activities was coded on a 0-7 sub-scale (ranging from not occurring $=0$ to very frequently occurring $=7$ ). The seven scores were aggregated to form an index with a possible range of 0-49 (Melhuish et al., 2008; Sylva et al., 2010). The higher the value, the better the quality of the early HLE. Based on this continuous scale, five HLE categories were created distinguishing very low (013) representing approximately $10 \%$, and very high scores (33-45) approximately $11 \%$. The other categories (low, medium, high) represented approximately $21 \%, 23 \%$ and $31 \%$ of the sample respectively. The early years HLE measure has been found to be a strong predictor of attainment and progress at various ages (Sammons et al., 2008a, 2008b, 2014a) and so was tested as a potential predictor in this AS/A-level follow up study. 
An academic Enrichment measure of HLE covering out of school learning opportunities was obtained from a questionnaire survey of EPPSE students conducted at age 14. This was based on aspects such as reading on your own for pleasure, going on educational visits with family and going to the library rated on four point Likert type scales based on the frequency of activities. The measure was created based on exploratory and confirmatory factor analysis (Chronbach alpha 0.72,) Further details are reported in Sammons et al., (2014a, 2014b); Sammons, Toth \& Sylva, 2015). It was found to predict attainment at age 16 for the full EPPSE sample and thus was included as a potential predictor in this study.

\section{Pre-school quality}

The English extension of the Early Childhood Environment Rating Scale (ECERS-E) developed by Sylva, Siraj-Blatchford, \& Taggart, (2003) reflects the quality of pre-school provision intended to support children's learning outcomes in successive versions of the Early Years Foundation Stage (EYFS) in England (https://www.gov.uk/early-yearsfoundation-stage) The areas of learning covered by the EYFS are: communication and language, physical development, personal, social and emotional development, literacy, mathematics, understanding the world, and expressive arts and design.

The ECERS-E instrument is based on structured observations by trained researchers to cover different aspects of quality and provided an overall quality score for each pre-school attended by the EPPSE sample (Sylva et al., 2006). The EPPSE sample was divided into groups of children whose pre-school experience could be classified as ranging from none (i.e., the 'home' group) through low, medium and high quality, based on individual pre-school centres' ECERS-E scores. The classification was based on the original distribution of the total ECERS-E scores for the 141 pre-school centres from which the EPPSE pre-school sample were recruited (a no quality category was given to the home group, lowest quality was defined as scores in the bottom $20 \%$, medium quality covered the middle $60 \%$ and highest quality scores in the top $20 \%$ of the distribution of centre scores). The percentages of EPPSE students drawn from these pre-school quality groups was slightly different reflecting differences in numbers of children recruited in the relevant age group amongst centres: no pre-school (10\%) low quality (14\%), medium quality (54\%) and high quality $(22 \%)$.

Earlier EPPSE research revealed that outcomes for children from the low quality group were little different to those of the no pre-school group, but the experience of high quality preschool was found to predict better child outcomes through primary and into secondary education (Anders et al., 2011; Hall et al., 2013; Sammons et al., 2008a and b; 2014a; Sylva et al., 2011). Given this, it was deemed important to test whether pre-school quality was a significant predictor in the follow up models of EPPSE students' later AS/A-Level outcomes.

\section{Primary school academic effectiveness}

Contextualised value added (CVA) effectiveness measures for primary schools attended by children in the EPPSE sample were derived from multilevel analyses of NPD data for all primary schools in England linking national cohorts of students' Key Stage 1 (taken at age 7)and Key Stage 2 (age 11) national assessment results. Separate indicators were calculated for individual primary schools in the core curriculum subjects English, mathematics and science (Melhuish et al., 2006). These analyses provided overall measures (residual estimates) of the academic success of individual primary schools in promoting their 
students' academic progress and these were averaged across three consecutive years (2001-2003). For each EPPSE child, these school based CVA measures were matched by schools' national DfE identifiers to provide indicators of the 'academic quality' of the primary school they attended. Categories of 'low', 'medium' and 'high' primary school academic effectiveness were created based on the distribution of schools' residual scores below one standard deviation, within (+/- I SD), and above one standard deviation from the mean. EPPSE children who attended academically more effective primary schools showed significantly better attainment and had made greater progress from age 7 to 11 than those who had attended less academically effective primary schools (Sammons et al., 2008; 2013), after control for differences in their backgrounds. Based on this, the primary school academic effectiveness measures were included in the list of potential predictors to be tested in the AS/A-level follow up.

\section{Secondary school quality}

The Office for Standards in Education (Ofsted) is the national inspection agency in England. All schools are inspected on a regular cycle and results published to inform parents' choice of school. Trained inspectors use a published inspection Framework and make various judgements of schools' quality. This included an overall judgment of the quality of student learning and an overall judgment of students' attendance at the time EPPSE students were in secondary school. Inspectors allocated schools to one of four grades (Outstanding, Good, Satisfactory or Requires improvement). Data on the most recent inspection judgments was matched for all secondary schools attended by students in the EPPSE sample when they were age 14 to provide indicators of the quality of their secondary school based on these official judgments. The quality of secondary school attended (as judged by inspectors) was found to predict EPPSE students' attainment and progress during Key Stage 3 and Key Stage 4 (Sammons et al., 2014a) and therefore Ofsted measures were included as potential predictors of later AS/A-level outcomes.

\section{Students' experiences of secondary school}

A self-report student questionnaire (Life in Year 11) was developed to investigate EPPSE students' views and experiences of secondary school. It included selected items from the following surveys: the School Climate Assessment Instrument (Grosin and McNamara 2001) and the Louisiana ABC+ model (Teddlie, Kochan and Taylor, 2002).

Exploratory and confirmatory factor analysis were used to create five measures of students' secondary school experiences. The items linked to these five measures (latent variables) are shown in Figure1 (for details see Sammons et al., 2014b). Four of the five measures relate to EER evidence on factors found to be important in defining the quality of teaching (Muijs et al., 2014) These measures have already been identified as significant predictors of EPPSE students' GCSE results at age 16 (Sammons et al., 2014a) and they were included as potential predictors of later AS/A-level results to establish how far such features linked to the quality of teaching continue to shape attainment in the longer term.

\section{Figure 1: Measures of EPPSE students' secondary school experiences (latent variables based on CFA) based on Year 11 Questionnaire survey}




\begin{tabular}{|c|c|c|}
\hline Teacher professional focus & Positive relationships & Monitoring students \\
\hline $\begin{array}{l}\text { If a pupil is bullied, they would feel } \\
\text { able to tell a teacher about it. } \\
\text { Teachers... } \\
\text {..spend all of the time in lessons } \\
\text { teaching us or making sure we are } \\
\text { working } \\
\text {..have the same rules about } \\
\text { behaviour } \\
\text {..come to their lessons on time } \\
\text {..mark and return homework } \\
\text { promptly } \\
\text {..make sure that it is quiet and } \\
\text { orderly during lessons } \\
. . \text { believe that learning is important } \\
\text { Cronbach }=0.77\end{array}$ & $\begin{array}{l}\text { Teachers... } \\
\text {..treat the pupils fairly } \\
\text {..are interested in me as a person } \\
\text {..school show respect for the pupil } \\
\text { The teachers and pupils get on } \\
\text { well }\end{array}$ & $\begin{array}{l}\text { I am set targets for my learning by my } \\
\text { teachers which are individual to me and } \\
\text { not for the whole class } \\
\text { The school has rewards for pupils who } \\
\text { work hard or make good progress even } \\
\text { if they do not get high grades } \\
\text { A pupil who works hard or makes good } \\
\text { progress is noticed and praised } \\
\text { Teachers notice those pupils who are } \\
\text { not working as well as they could and try } \\
\text { to make them work harder } \\
\text { Cronbach }=0.69\end{array}$ \\
\hline Formative feedback & \multicolumn{2}{|c|}{\begin{tabular}{|l|l} 
& Academic ethos
\end{tabular}} \\
\hline $\begin{array}{l}\text { Teachers.. } \\
\text {..help me when I am stuck } \\
\text {..make helpful comments on my wo } \\
\text {..tell me how to make my work bett } \\
\text { Cronbach }=0.8\end{array}$ & & $\begin{array}{l}\text { Most pupils.. } \\
\begin{array}{l}\text {..want to do well in exams } \\
\text {..want to continue their education after GCSEs } \\
\text {...are interested in learning } \\
\text { Cronbach }=\mathbf{0 . 7 8}\end{array} \\
\end{array}$ \\
\hline
\end{tabular}

\section{Social disadvantage}

There are limitations in using single measures of disadvantage, particularly relying only on the free school meals (FSM) poverty criteria in studying equity in education (Ilie, Sutherland and Vignoles, 2017). To identify students who would form the more 'disadvantaged' group in the EPPSE sample for the purposes of the AS/A-Level follow up study, multiple individual measures were included: FSM status; low family SES (based on the Registrar General's five point classification of parents' occupations into different levels ranging from 'Professional non-manual' to 'Unskilled manual', and also including the additional categories of 'Unemployed' and 'Never worked'); parents' combined salary band; parents' highest educational qualification level; parents' employment status (in work or not in work); and two indicators of neighbourhood disadvantage linked to home address post code, the Income Deprivation Affecting Children Index (IDACI) and the Index of Multiple Deprivation - (IMD). In addition, an EPPSE measure of students who had experienced multiple disadvantage (described below) was adopted as another criteria. Taken together, this means that both 'family' and 'place' (neighbourhood) drivers of educational outcomes are included in the overall definition of the 'disadvantaged' student group (Sammons, Toth and Sylva, 2015a).

The EPPSE research team had previously created its own multiple disadvantage index to classify all the individual children in the sample based on their own and their family characteristics (Table 1). This summary measure predicted the likelihood of special educational needs (SEN) identification in primary school and was associated with poorer educational outcomes across different phases of education up to age 16 (Hall et al., 2009; 2010 Sammons et al., 2004; 2014a; Sylva et al., 2010; Taggart et al., 2006). The EPPSE multiple disadvantage index was based on the summed score (presence/absence) for the characteristics listed in Table1, higher scores on the index predicted an increase likelihood of low attainment at school entry (age 5) and at later ages and increased likelihood of SEN. (For details see Sammons et al., 2002; Hall et al., 2010). Children who scored on three or more of the items in Table 1 were classed as multiply disadvantaged.

Table 1: Measures included in the EPPSE Multiple Disadvantage Index 


\section{Child variables}

- First language: English as an additional language (EAL)

- Large family: 3 or more siblings

- Pre-maturity / low birth weight

\section{Parent variables}

- Mother's highest qualification level: no qualifications

- Social class of father's occupation: Semi-skilled, unskilled, never worked, absent father or father not employed

- Young Mother (Age 13-17 at birth of EPPE child)

- Lone (single) parent

- Mother not working / unemployed

- Low Early years Home learning environment(HLE)

\section{Academic outcomes}

A summary indicator of academic 'success' at the end of primary schooling was chosen to identify children who showed higher than expected attainment in national assessments at age 11 (year 6). Obtaining Level 5 or better in national assessments in one or more of the three 'core' subjects (English, maths or science) was adopted as the criteria for defining 'high achievement' for students in the sample at the end of primary schooling. Level 5 was chosen because the benchmark expectation for national assessments was set at Level 4 in these three core subjects during this period. It was decided to adopt a broad definition of high attainment (Level 5+ on any of the core subjects) since this was in accord with official definitions of above average attainment, allows for children who show particular strength in only one domain (e.g. maths but not English or vice versa) to be included and provide a sufficiently large group for further analysis when classified by the disadvantage measure.

Data on EPPSE students' attainment in GCSE public examinations taken at age 16 (year 11) the end of compulsory schooling for the sample, and in Advanced-Level public examinations (AS/ A-levels) taken at age 17 and 18 respectively were also analysed. The research used benchmark measures of achievement including obtaining $5 A^{*}-C$ GCSE results, including English and mathematics; taking 4 or more AS levels (at age 17); taking 3 or more A-levels (at age 18).

In addition to the initial descriptive analyses to identify the two focal groups of students of interest for the analysis of Advanced level outcomes (high achieving disadvantaged students and high achieving non-disadvantaged students identified at age 11), multilevel logistic regression, multiple and logistic regression were used. Models were created to predict differences in students' national assessment outcomes at the end of primary school (at age 11) and their later examination results at GCSE, AS and A-level (Sammons, Toth and Sylva, 2015a). Models were run in STATA 13. Various dichotomous dependent variables were modelled (being classified as a 'high attainer' at age 11; Achieving 4 or more AS levels at age 17; Achieving 3 or more A-Levels at age 18). Further multilevel regression models of students' GCSE attainment at age 16 are shown in the Appendix but results are not discussed in this paper as the focus is on the predictors of Advanced level outcomes that could enable entry into HE. Missing data was excluded (the only measures with significant levels of missing data were the five based on the student surveys where a response rate of 
59.9\% was achieved in Year 11 and therefore the models that tested these predictors were based on a reduced sample, see Appendix for details of each model).

The main EPPSE study used a mixed methods EER design (Sammons et al., 2005) but the AS/A-level follow up in this paper employs only quantitative methods as only quantitative data were available from the NPD. Multilevel analysis was adopted to reflect the nesting of educational data (students in schools) where appropriate. The original EPPSE pre-school sample was clustered at the pre-school level However, the children moved into over 700 primary schools and later over 300 secondary schools. The numbers of EPPSE students in any one primary or secondary school were typically very small, however, multilevel analysis indicated that controlling for the effects of clustering improved the model fit in analyses of the full sample (only 2 levels were possible, students nested within schools since the numbers were insufficient for cross classified analysis). Odds ratios (OR) were calculated for the logistic regression models to show the effects of different predictors in increasing or decreasing the likelihood of academic 'success', defined by the Level 5 attainment criteria at age 11 or as reaching benchmarks that defined good enough AS/A-level examination results that could enable entry to HE ( Sammons, Toth and Sylva, 2015a).

\section{Results}

The present investigation identified a group of 'bright' (high attaining ) but disadvantaged students at the end of primary schooling to follow up and establish what predicted their later attainment in Advanced level qualifications at age 17/18 based on the measures described previously as will be described below.

\section{Identifying the disadvantaged group}

The classification of the 'disadvantaged' group was made using multiple background characteristics including FSM status in Year 6 and Year 9, family SES at four time points based on parents' highest employment status (entry to the study, ages 7, 11 and 14), low parental salary or no earned income (measured at age 7) and whether they were classed as multiply disadvantaged on the composite measure index shown in Table 1. Just under half, $49 \%(n=1,550)$ of the original EPPSE sample were classified as relatively disadvantaged on one or more of these different criteria.

In terms of background characteristics for the disadvantaged group, it was found that:

- $89 \%$ of parents of this selected subsample reported they had no earned income or their joint salary was below $£ 15,000$ (measured when children were age 7);

- $60 \%$ recorded a score of 3 or more on the EPPSE multiple disadvantage index criteria listed in Table 1;

- 55\% had low family SES (based on parents' level of employment being in the categories of semi-skilled or unskilled manual, not working or unemployed) at age 7 .

Identifying the 'bright' but disadvantaged group

As noted above we defined as 'bright' (based on relatively high attainment) those children who had obtained Level 5 or more on any of the three 'core' subjects - English, maths or science, in national assessments conducted at the end of Year 6 . The total number meeting 
this criterion was 1058 representing a third (33\%) of the EPPSE sample for whom complete data were available for the analysis of attainment at age 11 (national assessment data were matched for 3153 of the original 3172 EPPSE children, over $99 \%)$. About $40 \%(n=422)$ of the 1058 students classified as high attainers at age 11 had obtained Level 5 or more on all three core subjects, $29 \%(n=311)$ on two subjects and $31 \%(n=325)$ on one subject.

\section{Table 2: Distribution of 'high attainers' by disadvantage classification within the EPPSE sample at age 11}

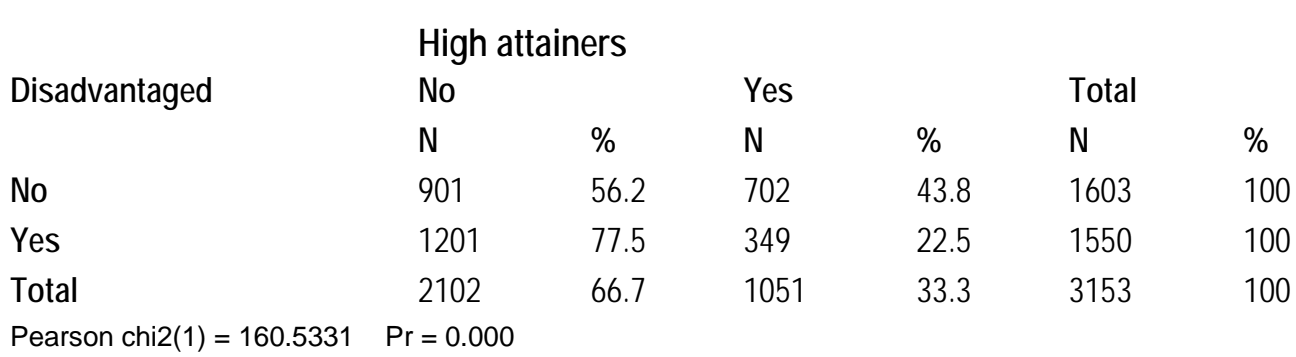

Table 2 shows how many of the 1,550 children classified as disadvantaged were identified as high attainers at age 11 . This group was named 'bright but disadvantaged' at age 11 . As expected given the widespread evidence of an equity gap in the literature, the disadvantaged group were significantly less likely to show high attainment at age 11 than their more advantaged peers. Less than a quarter $(22.5 \%, n=349)$ of the 1550 disadvantaged children were classed as high attainers. This compares with over two fifths $(43.8 \%)$ of the non-disadvantaged children in the EPPSE sample. These figures highlight the association between disadvantage and student attainment and extent of the marked equity gap at the end of primary school, indicating that disadvantaged children were much less likely to have obtained above average results (Level 5+) in Key Stage 2 national assessments in England.

The high achieving disadvantaged group of students were found to be much more likely to receive FSM than the high achieving non-disadvantaged group (26\% versus $2 \%$ in Year 6 and $27 \%$ versus $3 \%$ in Year 9). They were also much more likely to be from families with low incomes ( with a family salary below $£ 15,000$ or no salary (91\% versus $4 \%$ ), to come from families with low SES (28\% versus $4 \%$ ) and to have experienced multiple disadvantages as defined by the EPPSE index (51\% versus $1 \%$ ) than their more advantaged high attaining peers at age 11. Proportionately fewer of the bright but disadvantaged group were of white UK ethnic origin (63\%), compared to their bright but non-disadvantaged peers ( $85 \%$ white UK).

\section{Following up the 'bright' but disadvantaged children into secondary school and modelling their AS and A-level success}

The follow up analysis reports the AS and A-level outcomes for the focus sub-group of disadvantaged children classified as high achievers at the end of primary school $(n=349)$ and makes comparisons with high achieving children in the who were not classified as disadvantaged $(n=702)$. Logistic regression models were used to analyse the data for the high achieving disadvantaged group (due to the small numbers at the individual secondary school level for this sub-group multilevel models were not fitted). 
Obtaining good GCSE results at age 16 is an important pre-requisite for progression into Advanced level courses and shapes students' post 16 destinations (Sylva et al., 2014). Additional analyses for the high attaining disadvantaged group demonstrate that 'good' educational experiences (based on student self-report data) in lower secondary school enhanced the likelihood of better GCSE outcomes at age 16 (see Sammons, Toth and Sylva 2015a). Enrichment experiences in Key Stage 3 also remained influential. Many schools and colleges required students to have achieved success in terms of the benchmark ' $5 A^{*}-C$ GCSE including English and mathematics' at 16 to enter AS and A-level study. Obtaining the GCSE benchmark and then going on to take AS-levels were therefore important preconditions for full A-level study.

\section{AS-level outcomes}

Students in the high attainment disadvantaged group were much less likely to go on to attain four or more AS-levels when compared with the equivalent high attaining but more advantaged student group ( $36 \%$ versus $61 \%$ ) as shown in Table 3 . Proportionately more were found in the 'KS5 data unavailable' category (this indicates that students did not stay on to enter any AS courses post 16 at either school or college and thus no longer appeared in the official NPD records).

Table 3: Later AS-level outcomes for the high attainment student group compared by disadvantage classification

\begin{tabular}{|c|c|c|c|c|c|c|c|c|c|c|}
\hline \multirow{3}{*}{$\begin{array}{l}\text { High } \\
\text { attainment } \\
\text { disadvantaged } \\
\text { children }\end{array}$} & \multicolumn{10}{|c|}{ Attained 4 or more AS-levels? } \\
\hline & \multicolumn{2}{|c|}{ No AS } & \multicolumn{2}{|c|}{$\begin{array}{l}\text { Less than } \\
\quad 4 \text { AS }\end{array}$} & \multicolumn{2}{|c|}{$\begin{array}{l}\text { Four or } \\
\text { more AS }\end{array}$} & \multicolumn{2}{|c|}{$\begin{array}{c}\text { KS5 Data } \\
\text { unavailable }\end{array}$} & \multicolumn{2}{|c|}{ Total } \\
\hline & $\mathbf{N}$ & $\%$ & $\mathbf{N}$ & $\%$ & $\mathbf{N}$ & $\%$ & $\mathbf{N}$ & $\%$ & $\mathbf{N}$ & $\%$ \\
\hline No & 60 & 8.5 & 137 & 19.5 & 426 & 60.7 & 79 & 11.3 & 702 & 10 \\
\hline Yes & 47 & 13.5 & 81 & 23.2 & 126 & 36.1 & 95 & 27.2 & 349 & 10 \\
\hline Total & 107 & 10.2 & 218 & 20.7 & 552 & 52.5 & 174 & 16.6 & 1051 & 10 \\
\hline
\end{tabular}

Logistic regression models revealed that those high attainer disadvantaged students who did attain four or more AS-levels ( $n=126$ out of the 349 in this group) were significantly more likely to be girls (OR 1.67) and relatively less likely to be of white UK background. Although the numbers of students in different ethnic groups were quite small the OR for all ethnic groups compared with White UK group were positive and sizeable. The largest significant effects were for the Black African (OR 7.46), White European (OR 6.39), and Indian (OR 5.52) groups compared to White UK (see Table 4).

Table 4. Logistic regression model showing child and family predictors of attaining four or more AS-levels for the disadvantaged high attaining student group

$\begin{array}{lrrrr}\quad \text { Predictors } & \text { Coef. } & \text { Std. Error } \begin{array}{l}\text { Odds } \\ \text { Ratios }\end{array} & \text { Sig. } \\ \text { Age } & 0 & 0.04 & 1.00 \\ \text { Gender } & 0.51 & 0.25 & 1.67 \text { * } \\ \begin{array}{l}\text { Ethnic group (compared to White UK) } \\ \text { White European Heritage }\end{array} & 1.85 & 0.93 & 6.39 \text { * }\end{array}$




\begin{tabular}{|c|c|c|c|c|}
\hline Black Caribbean Heritage & 0.61 & 0.47 & 1.83 & \\
\hline Black African Heritage & 2.01 & 0.78 & 7.46 & ** \\
\hline Any Other Ethnic Minority & 1.65 & 0.56 & 5.18 & ** \\
\hline Indian & 1.71 & 0.61 & 5.52 & ** \\
\hline Pakistani & 0.62 & 0.45 & 1.86 & \\
\hline Bangladeshi & 0.39 & 0.89 & 1.48 & \\
\hline Mixed Race & 0.59 & 0.46 & 1.81 & \\
\hline \multicolumn{5}{|c|}{ KS3 home learning enrichment (compared to low) } \\
\hline KS3 home learning enrichment medium & 1.31 & 0.29 & 3.71 & *** \\
\hline KS3 home learning enrichment high & 1.33 & 0.39 & 3.79 & *** \\
\hline Intercept & -1.73 & 0.23 & & *** \\
\hline Number of students & 349 & & & \\
\hline Deviance (-2 x Log Restricted-Likelihood) & 401 & & & \\
\hline
\end{tabular}

${ }^{\star} p<0.05,{ }^{* *} p<0.01,{ }^{* \star *} p<0.001$

The experience of Enrichment activities during Key Stage 3 increased the likelihood of students in this group later attaining four or more AS-levels nearly fourfold (OR 3.79 for the high versus low Enrichment category). However the early HLE measure was not found to be statistically significant. This is in contrast to findings at younger ages as it had predicted better GCSE results for all students and for the high attaining disadvantaged group at age 16 (see Sammons et al., 2014a; Sammons, Toth and Sylva, 2015a and GCSE models in the Appendix).

Various pre-school, primary school and secondary school measures of the quality of students educational experiences in different phases of education were separately tested in the logistic regression models. Table 5 presents the results for the measure of pre-school quality based on the ECERS-E measure as an example. Both medium (OR 2.60) and high quality (3.58) pre-school experience (compared to none) showed significant positive effects on the likelihood of obtaining 4 or more AS, whereas the effect of low quality pre-school though positive was not significantly different from the effect of no pre-school.

Table 5: Logistic regression model showing child and family predictors of attaining four or more AS-levels for the disadvantaged high attaining student group and testing Pre-school quality as predictor

\begin{tabular}{|c|c|c|c|c|}
\hline & Coef. & Std. Error & $\begin{array}{l}\text { Odds } \\
\text { Ratios }\end{array}$ & Sig. \\
\hline Age & 0 & 0.04 & 1.00 & \\
\hline Gender & 0.56 & 0.26 & 1.75 & * \\
\hline \multicolumn{5}{|c|}{ Ethnic group (compared to White UK) } \\
\hline White European Heritage & 1.7 & 0.93 & 5.50 & \\
\hline Black Caribbean Heritage & 0.44 & 0.48 & 1.55 & \\
\hline Black African Heritage & 2.09 & 0.8 & 8.05 & ** \\
\hline Any Other Ethnic Minority & 1.51 & 0.57 & 4.55 & $\star *$ \\
\hline Indian & 1.92 & 0.64 & 6.82 & ** \\
\hline Pakistani & 0.92 & 0.49 & 2.51 & \\
\hline Bangladeshi & 0.38 & 0.92 & 1.46 & \\
\hline Mixed Race & 0.51 & 0.47 & 1.66 & \\
\hline
\end{tabular}


KS3 HLE enrichment medium

KS3 HLE enrichment high

Pre-school quality-ECERS-E (compared to no pre-school)

Low quality

Medium quality

High quality

Intercept

Number of students

Deviance (-2 x Log Restricted-Likelihood)

$\begin{array}{rrrr}1.34 & 0.29 & 3.82 & * \star * \\ 1.44 & 0.4 & 4.22 & * \star *\end{array}$

$\begin{array}{lll}0.57 & 0.6 & 1.77\end{array}$

$0.96 \quad 0.48 \quad 2.60$ *

$1.28 \quad 0.52 \quad 3.58$ *

$-2.69 \quad 0.51$

349

393

The quality of the secondary school attended (measured by Ofsted inspection grades) also predicted better AS outcomes for the high attaining disadvantaged group (Table 6). Having attended a secondary school rated by as 'outstanding' rather than 'inadequate' in Ofsted judgments of the 'quality of learning' the school provided, when students were in lower secondary education (Key Stage 3) increased the probability of students later attaining the AS benchmark threefold (OR 3.50). The primary school value added measure of school quality in terms of academic effectiveness was found to increase the chances of disadvantaged children being identified as high attainers at age 11 (see Appendix) and was an important predictor of attainment at age 11 and at age 14 in earlier analyses for the whole EPPSE sample (Sammons et al; 2008b; 2013; 2014). However, it did not predict the high attaining disadvantaged group's later AS success when tested in the logistic regression model, indicating that its apparent protective effects did not remain influential beyond the end of compulsory education in terms of academic success at age 17 and 18.

Table 6: Logistic regression model showing child and family predictors of attaining four or more AS-levels for the disadvantaged high attaining student group and testing secondary school quality as a predictor

\begin{tabular}{|c|c|c|c|c|}
\hline & Coef. & Std. Error & $\begin{array}{l}\text { Odds } \\
\text { Ratios }\end{array}$ & \\
\hline Age & 0.01 & 0.04 & 1.01 & \\
\hline Gender & 0.47 & 0.26 & 1.61 & \\
\hline \multicolumn{5}{|c|}{ Ethnic group (compared to White UK) } \\
\hline White European Heritage & 1.98 & 0.92 & 7.26 & * \\
\hline Black Caribbean Heritage & 0.56 & 0.48 & 1.75 & \\
\hline Black African Heritage & 2.15 & 0.79 & 8.55 & ** \\
\hline Any Other Ethnic Minority & 1.79 & 0.57 & 6.02 & ** \\
\hline Indian & 1.44 & 0.65 & 4.21 & * \\
\hline Pakistani & 0.73 & 0.46 & 2.07 & \\
\hline Bangladeshi & 0.52 & 0.89 & 1.68 & \\
\hline Mixed Race & 0.65 & 0.46 & 1.91 & \\
\hline \multicolumn{5}{|c|}{ KS3 HLE enrichment (compared to low) } \\
\hline KS3 HLE enrichment medium & 1.29 & 0.29 & 3.62 & $* * *$ \\
\hline KS3 HLE enrichment high & 1.28 & 0.4 & 3.60 & ** \\
\hline \multicolumn{5}{|c|}{$\begin{array}{l}\text { Ofsted secondary school quality: Quality of learning } \\
\text { (compared to inadequate) }\end{array}$} \\
\hline Outstanding & 1.25 & 0.57 & 3.50 & * \\
\hline Good & 0.47 & 0.37 & 1.61 & \\
\hline
\end{tabular}




$\begin{array}{lrrr}\text { Satisfactory } & 0.25 & 0.34 & 1.28 \\ \text { Intercept } & -2.04 & 0.35 & \\ \text { Number of students } & 349 & & \\ \text { Deviance (-2 x Log Restricted-Likelihood) } & 396 & & \end{array}$

The bright but disadvantaged group showed better outcomes at AS if they had reported positive educational experiences in lower secondary school based on four of the five measures tested. Table 7 summarises effects for each of the measures identified as significant in the logistic models. (Note: Due to sample size limitations these 5 measures were tested separately while controlling for the same set of child and family predictors reported in the logistic regressions shown in Table 3). For example, when students in the high attainment disadvantaged group reported that teachers focused on learning and were competent (Teacher professional focus), that relationships between students and teachers were good in terms of trust, respect and fairness (Positive relationships), there were higher levels of monitoring of their work by teachers (Monitoring students) and greater levels of teacher feedback on their work (Formative feedback) they were more likely to attain four or more AS levels. The strongest effect (OR 2.99) was for Positive relationships followed by the Formative feedback measure (OR 2.35). These findings point to the importance of high quality teaching and learning experiences in secondary school for the high achieving disadvantaged group of students if they are to continue on succeed in AS studies post 16. Details of earlier findings on these student self-report measures and effects on GCSE results for the full EPPSE sample are found in Sammons et al. (2014a \& b)

Table 7: Summary of logistic regression effects for measures of students' secondary school experiences in year $\mathbf{1 1}$ as predictors of attaining four or more AS-levels

Teacher professional focus (continuous)

Positive relationships (continuous)

Monitoring students (continuous)

Formative feedback (continuous)

${ }^{*} p<0.05,{ }^{* *} p<0.01,{ }^{* * *} p<0.001$
Coef.

0.82

1.09

0.82

0.86
Std. Error

Odds Ratios

0.412 .27 *

$0.42 \quad 2.99$ **

0.372 .28 *

0.342 .35 *

\section{A-level attainment}

Disadvantage remained a strong influence on the likelihood of students entering three or more A-Levels (the typical standard expected for university entry) in line with findings already reported for the AS benchmark and again indicating the strength and persistence of the equity gap. High attaining disadvantaged students were significantly less likely to go on to attain three or more A-levels at age 18 when compared with the group of high attaining more advantaged students as shown in Table 8 . Only $35 \%$ of the high attaining but disadvantaged group attained 3 or more A-levels. By contrast, the figure was 60 per cent for the high attaining but non-disadvantaged group.

Table 8: Number of A-levels attained by the high attaining student sample comparing the disadvantaged and non-disadvantaged student groups 


\begin{tabular}{|c|c|c|c|c|c|c|c|c|c|c|}
\hline \multirow{3}{*}{$\begin{array}{l}\text { High achiever } \\
\text { disadvantaged } \\
\text { students }\end{array}$} & \multicolumn{8}{|c|}{ Attained three or more } & \multirow{2}{*}{\multicolumn{2}{|c|}{ Total }} \\
\hline & \multicolumn{2}{|c|}{ No $A$} & \multicolumn{2}{|c|}{$\begin{array}{c}\text { Less than } 3 \text { A- } \\
\text { levels }\end{array}$} & \multicolumn{2}{|c|}{$\begin{array}{l}\text { Three or more } \\
\text { A-levels }\end{array}$} & \multicolumn{2}{|c|}{$\begin{array}{c}\text { KS5 Data } \\
\text { unavailable }\end{array}$} & & \\
\hline & $\mathbf{N}$ & $\%$ & $\mathbf{N}$ & $\%$ & $\mathbf{N}$ & $\%$ & $\mathbf{N}$ & $\%$ & $\mathbf{N}$ & $\%$ \\
\hline No & 122 & 17.4 & 79 & 11.3 & 422 & 60.1 & 79 & 11.3 & 702 & 100 \\
\hline Yes & 92 & 26.4 & 39 & 11.2 & 123 & 35.2 & 95 & 27.2 & 349 & 100 \\
\hline Total & 214 & 20.4 & 118 & 11.2 & 545 & 51.9 & 174 & 16.6 & 1051 & 100 \\
\hline
\end{tabular}

Nonetheless, certain individual and family characteristics predicted better attainment at Alevel for the high attaining disadvantaged group, as Figure 2 illustrates. Overall the findings from logistic regression models on the predictors of A-level success for the high attaining but disadvantaged student group were broadly similar to those described above for their ASresults. Girls were twice as likely to obtain the benchmark of three or more A-levels as boys (OR 2.08). Students who had high scores for the HLE Enrichment factor (reported reading in their own time and who participated in enriching activities at home at age 14) were also more likely to go on to attain three or more A-levels (OR 2.96 for high versus low score on the Enrichment measure). The Ofsted inspection indicator of secondary school quality also remained a positive and significant predictor. Having attended an outstanding' rather than an 'inadequate' school at age 14 increased the likelihood of later going on to attain three or more A-levels at age 18 by four fold.

Figure 2: Odds ratios for individual, family factors and secondary school measures that predict attaining three or more A-levels for high achieving disadvantaged group

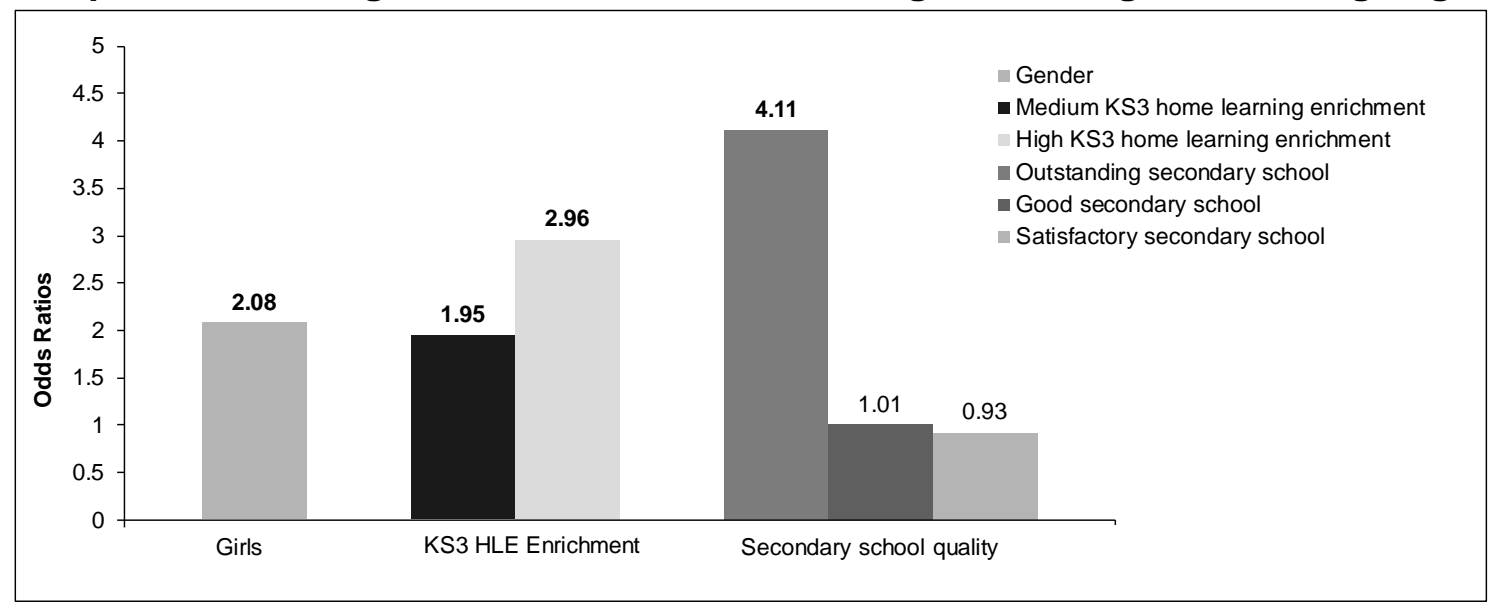

Note: Statistically significant ORs are in bold. See Table A.10 in Appendix for the full models.

However, none of the pre-school, the primary school or the four student self-report measures of secondary school experiences were significant predictors of gaining three or more Alevels at age 18 for the high attainment disadvantaged group when tested in the logistic regression models.

\section{Limitations of the research}

The EPPSE sample on which these analyses are based is relatively small, although it has been found to be broadly representative of children in England for key child and family characteristics in comparisons with DfE national data (Sylva et al., 2010). In addition, the numbers of children meeting the criteria for inclusion in the high attaining disadvantaged 
group limited the number of predictors that could be tested simultaneously in the logistic regression models.

England is known for the size of the equity gap in socio-economic measures of disadvantage. In studying the long term drivers of academic success, the specific historic context of the English education system and the availability of national data (the NPD linked measures of students' national assessment and public examination results and the Ofsted inspection judgments of quality for all schools) are not available in most other education systems. This high stakes accountability context focusing on the use of student and school performance data needs to be considered in interpreting findings.

In contrast to the mixed methods EER design of the main EPPSE study, no funding was available for additional collection of student surveys at the AS/A-level follow up or to resource case studies of individual students and families that had enriched the research findings at younger ages. Thus it was not possible to explore disadvantaged students' reasons for staying on to Advanced level study nor their perspectives on what helped or hindered their success.

EPPSE is not an intervention study so in contrast to a randomised controlled trial it is not possible to draw causal inferences. This means it is not appropriate to generalise the findings. The EPPSE project shows similarities with epidemiological research approaches since it studied naturally occurring variation in children's educational outcomes in real life educational contexts across different phases of education. Given this it can only identify statistical associations and factors that predicted educational success in the long term for this sample. Nonetheless, it is argued that the findings can inform policy makers about such patterns and predictors and so point to potentially fruitful areas for the design of future educational interventions and improvement strategies to promote greater equity in educational outcomes.

\section{Discussion and Conclusions}

This research drew on a broadly representative longitudinal sample of children in England that had been tracked previously across different phases of education from age 3 to 16 . It focused on these students' attainment in AS/A-level outcomes that are important prerequisites for entry into HE in the English system. It identified a group of children classed as 'bright' (relatively high attaining) but disadvantaged at the end of primary school whose later AS/A-level outcomes were compared with a similarly high attaining but nondisadvantaged group. A particular aim was to illuminate the drivers of later academic success for the high attaining disadvantaged student group through logistic regression analyses of predictors for two benchmark indicators of Advanced level attainment.

It is notable that although early learning experiences (based on activities captured by the early HLE measure) predicted the likelihood of disadvantaged children being identified as in the high attainers group at age 11, the early HLE measure did not predict better Advanced level outcomes for this focus group. However, the Enrichment measure of out of school learning reflecting a better HLE in lower secondary school showed significant positive effects for success in both the AS and A-level benchmarks for the high attainment disadvantaged group. The findings suggest different forms of HLE support may have different effects at 
different ages, so a focus only on the early years HLE is unlikely to be sufficient to promote longer term academic success up to age 18.

There was evidence of positive long terms effects of pre-school for the focal group of interest in this paper for later AS success. Higher quality HLE learning experiences both at home and in pre-school may act as protective influences and can be seen as potentially fostering resilience by boosting the attainment of disadvantaged children across different phases of education (so reducing the equity gap in achievement). An implication of this finding is that access to high quality pre-school can be viewed as forms of 'social intervention' that may ameliorate the adverse effects of disadvantage. Evaluations of policy initiatives aimed at enhancing equity should address HLE support at different ages, not just in the early years, and the role of high quality pre-school as foci for educational interventions for disadvantaged children.

Longitudinal research also conducted in England by Crawford, Macmillan and Vignoles (2017) pointed to the importance of lower secondary education and transition to secondary school for high achieving poor students up to age 16 based on a very large national sample. Their research revealed continued divergence in the performance of initially high achieving students up to age 16 in GCSE outcomes. They argued that secondary schools play a part in shaping differences in trajectories for disadvantaged students and highlighted implications for policy to ensure such students have greater access to 'good' schools. The present study supports and extends their work. It also focused on a high attaining sample of disadvantaged children identified in primary school and also highlights divergence in outcomes in terms of the equity gap evident in their later AS/A-level outcomes that are required for HE entry. It extends understanding by using the smaller EPPSE sample for which much more detailed information about both home and educational influences was available, and by following up students' beyond GCSE ( reported by Sammons, Toth and Sylva, 2015a) to explore the drivers of their AS and A-level outcomes.

Our findings confirm that even though they did well at age 11, this group of high attaining disadvantaged students remained at much greater risk of lower achievement in the longer term. Nonetheless, a number of school influences increased their chances of Advanced level success. These can also be seen as factors that may promote resilience in addition to the pre-school and HLE experiences noted above.

Going to a 'better' secondary school (identified by Ofsted quality ratings) during lower secondary education predicted better AS/A-level success subsequently. This supports and extends findings by Crawford, MacMillan and Vignoles (2017). Improving the quality of schools serving more disadvantaged communities and their access to better secondary schools is likely to be beneficial in boosting attainment in the longer term and therefore enhancing higher education opportunities for such disadvantaged students.

Ofsted global ratings cannot illuminate the features of secondary school experiences that may be important for the high attaining disadvantaged students, however. Various measures of their earlier secondary school experiences (derived from self-reports) were tested. Experiences that were significant predictors of later AS success (but were not significant for the A-level benchmark) included the factors measuring 'Positive relationships' with teachers, 'Teachers' professional focus' 'Formative feedback' about their work and teachers 
'Monitoring students' work'. These findings are in accord with EER theoretical models and empirical findings that highlight the importance of teaching and learning processes in shaping students' attainment. These four factors align well with concepts identified by Muijs et al's, (2014) 'state of the art' review of teacher effectiveness. An implication for school improvement is the use of such student self-report measures to inform school self-evaluation and improvement activity, particularly if such school review compares responses from disadvantaged and less disadvantaged students and focuses on raising the quality of teaching and feedback, and fostering positive student teacher relationships for disadvantaged students, as these factors were found to be predictors of their later success in this study.

The finding on the positive effects of the Enrichment HLE measure noted above also has implications for secondary schools because disadvantaged students usually have fewer enrichment opportunities at home. Extra resources and support to encourage reading for pleasure, educational trips, cultural activities and additional learning opportunities for studying at school (perhaps through extra after school provision) may prove beneficial interventions to support disadvantaged students with limited out of school learning opportunities.

Girls and ethnic minority students in the high attaining but disadvantaged group showed better long term attainment in both AS and A-level success than boys and those from white UK backgrounds in this same focal group. An important implication for schools may be to ensure they create and target additional opportunities for white working class students, especially for white working class boys to foster their engagement and learning both in and out of school in order to counter their long term under-achievement at Advanced level that reduces their opportunities for HE entry.

This paper provides new evidence about what predicts long term success in AS and A-level outcomes for a purposive sample of high attaining disadvantaged students identified at age 11 and has highlighted the role of educational influences reflecting the quality of their experiences in and out of school across different phases from pre-school to the end of compulsory secondary education. Jackson et al (2007) have commented on both primary and secondary effects of background in accounting for the persistence of equity gaps in attainment for disadvantaged children. 'Secondary effects' are conceptualised as those linked to student or system 'choices' that further reinforce inequalities in outcomes. Our findings point to the role of differences in pre-school and school quality and secondary school experiences that are especially relevant for the continued success of the focal group of interest to this study. These quality measures had predicted attainment at younger ages for the full EPPSE sample and students' educational destinations post 16 in terms of 'choices' to stay on for an academic route (Sylva et al; 2010; 2014). The present results reveal their continued importance for longer term success in Advanced level qualifications for the high attaining disadvantaged group. The combination of better (or poorer) experiences may help to reduce or, conversely, exacerbate the risk of educational failure for such students. Kyriakides and Creemers (2011) argued fort further research to establish which features of schools and teaching help to promote effectiveness in terms of both equity and quality and the present findings provide some pointers of features found to be of particular importance for the high attaining students in this study. 
The research has some implications for the evaluation of interventions and strategies to enhance equity, specifically for disadvantaged students who are high attainers during primary school to reduce the risk of poorer outcomes in the longer term as they move through secondary school. It suggests that more attention should be given to enhancing access to 'better' quality schools and also to promoting the quality of both pre-school and school experiences across different phases of education. Evaluations of these features (through the use of inspection results, analysis of school performance data, and action to promote fairer admissions policies for schools) could inform policy approaches to promote greater equity. Practitioners in schools can address features identified by student self-report as important to enhance learning and attainment. Such approaches can complement the evaluation of more specific theory driven school improvement interventions such as those outlined by Charalambous, Kyriakides, and Creemers (2016) in relation to the Dynamic Approaches to School Improvement model and by other papers in this special issue.

\section{References}

Anders, Y., Sammons, P., Taggart, B., Sylva, K., Melhuish, E. \& Siraj-Blatchford, I. (2011). The influence of child, family, home factors and pre-school education on the identification of special educational needs at age 10, British Educational Research Journal, 37 (3), 421-441.

Anders, Y., Rossbach, H.G., Weinert, S., Ebert, S., Kuger, S., Lehrl, S., \& von Maurice, J. (2012). Home and preschool learning environments and their relations to the development of early numeracy skills. Early Childhood Research Quarterly, 27, 231-244.

Bradley R. H. (1994). The HOME Inventory: review and reflections. In H. Reese (ed) Advances in Child Development and Behavior, 25 (pp. 241-88). San Diego, CA: Academic.

Bradley, R. H., \& Caldwell, B. M. (1982). The consistency of the home environment and its relation to child development. International Journal of Behavioral Development, 5(4), 445465.

Bronfenbrenner, Urie (1989). "Ecological systems theory". In Vasta, Ross. Annals of Child Development: Vol. 6. London: Jessica Kingsley Publishers, 187-249.

Cattan, S., Crawford, C., and Dearden. L. (2014) The Economic Effects of Pre-school Education and Quality. Institute for Fiscal Studies. IFS Report R99 http://www.ifs.org.uk/uploads/publications/comms/R99.pdf

Causa, O. \& C. Chapuis (2009). Equity in student achievement across OECD countries: An investigation of the role of policies, OECD Economics Department Working Papers, No. 708.

Causa, O. \& Johansson, A. (2010). Intergenerational social mobility in OECD countries, OECD Journal: Economic Studies, 1-44.

Charalambous, E., Kyriakides, \& Creemers, B. (2016). Promoting quality and equity in socially disadvantaged schools: A group randomised study, Studies in Educational Evaluation doi: http://dx.doi.org/10.1016/j.stueduc.2016.06.001

Chowdry, H., Crawford, C., Dearden, L., Goodman, A., \& Vignoles, A. (2013). Widening participation in higher education: analysis using linked administrative data. Journal of the Royal Statistical Society: Series A (Statistics in Society), 176 (2), 431-457. 
Crawford, C., Macmillan, L., \& Vignoles, A. (2017). When, and why do initially high-achieving poor children fall behind? Oxford Review of Education, 43 (1) 88-108.

Creemers, B.P.M \& Kyriakides, L. (2008) The Dynamics of Educational Effectiveness, London: Routledge.

Creemers, B.P.M, Kyriakides, L. \& Sammons, P. (2010) Methodological Advances in Educational Effectiveness Research, London: Taylor \& Francis.

Ermisch, J. (2012). Latest international social mobility comparisons. Sutton Trust - report on Crita Project, London: Sutton Trust http://www.suttontrust.com/wpcontent/uploads/2012/09/sutton-trust-latest-international-social-mobility-comparisons.pdf

Grosin, L. and McNamara, P. (2001). 'Bedömningsinstrument för skolklimat (Assessment instrument for school climate)'. [Online]. Available at: http://www.mdh.se/isb/pedagogik/personal/peter_mcn/sv1.html [Last accessed 17 April 2002].

Gustaffson, J., Hansen, K. \& Rosen, M. (2011). Effects of Home Background on Student achievement in Reading Mathematics and Science, Chapter 4 in TIMSS \& PIRLS 2011 Relationships Report, TIMSS \& PIRLS International study Centre, Lynch school of Education, Boston College. https://timssandpirls.bc.edu/timsspirls2011/downloads/TP11 Chapter 4.pdf

Hall, J., Sammons, P., Sylva, K., Melhuish, E., Taggart, B., Siraj-Blatchford, I., \& Smees, R. (2010). Measuring the cumulative risk to children's cognitive development: Confirmatory factor analysis using formative measurement. British Journal of Developmental Psychology. 28, 219-238.

Hall, J., Sylva, K., Melhuish, E., Sammons, P., Siraj-Blatchford, I., \& Taggart, B. (2009). The role of pre-school quality in promoting resilience in the cognitive development of young children. Oxford Review of Education, 35 (3), 331-352.

Hall, J., Sylva, K., Sammons, P., Melhuish, E., Siraj-Blatchford, I. \& Taggart, B. (2013): Can preschool protect young children's cognitive and social development? Variation by centre quality and duration of attendance, School Effectiveness and School Improvement, 24 (92) 155-176.

Harms, T., Clifford, R. M., \& Cryer, D. (1998). Early Childhood Environmental Rating Scale, Revised Edition (ECERS-R). New York: Teachers College Press.

Ilie, S., Sutherland, A., \& Vignoles, A. (2017). Revisiting free school meal eligibility as a proxy for pupil socio-economic deprivation, British Educational Research Journal, 43 (2) 253-274.

Jackson M., Erikson R., Goldthorpe J.H., Yaish M. (2007). Primary and secondary effects in class differentials in educational attainment: The transition to A-level courses in England and Wales, Acta Sociologica, 50 (3), 211-229. 
Kyriakides, L. \& Creemers, B.P.M (2011) Ca schools achieve both quality and equity? Investigating the two dimensions of educational effectiveness, Journal of Education for Students Placed at Risk, 16 (4) 237-254.

Melhuish, E., Romaniuk, H., Sammons, P., Sylva, K., Siraj-Blatchford, I., \& Taggart, B. (2006). Effective Pre-school and Primary Education 3-11 Project (EPPE 3-11): The Effectiveness of Primary Schools in England in Key Stage 2 for 2002, 2003 and 2004. Full Report. London: Institute of Education, University of London.

Melhuish, E., Sylva, K., Sammons, P., Siraj-Blatchford, I., Taggart, B. \& Phan, M. (2008). Effects of the home learning environment and preschool center experience upon literacy and numeracy development in early primary school. Journal of Social Issues, 64 (1), 95-114.

Mortimore, P., Sammons, P., Stoll, L., Lewis, D. \& Ecob, R., (1994). School Matters: The Junior Years, London: Paul Chapman.

Muijs, D \& Reynolds, D (2003). Student background and teacher effects on achievement and attainment in mathematics: A longitudinal study, Journal of Educational Research and Evaluation, 9(3) 289-314.

Muijs, D., Kyriakides, L., van der Werf, G., Creemers, B., Timperley, H. \& Earl, L. (2014) State of the art - teacher effectiveness and professional learning, School Effectiveness and School Improvement, 25:2, 231-256.

OECD (2013), PISA 2012 Results: Excellence Through Equity: Giving Every Student the Chance to Succeed (Volume II), PISA, OECD Publishing

Reynolds, D., Sammons, P., De Fraine, B., Van Damme, J., Townsend, T., Teddlie, C. \& Stringfield, S. (2014). Educational effectiveness research (EER): A state-of-the-art review, School Effectiveness and School Improvement, 25 (2), 197-230.

Sammons, P. (1995), Gender, Ethnic and Socio-Economic Differences in Attainment and Progress: A longitudinal analysis of student achievement over nine years, British Educational Research Journal, 21, (4) pp. 465-485.

Sammons, P. (2010). Equity and Educational Effectiveness. In P. Peterson, E., Baker \& B. McGaw (Editors) International Encyclopedia of Education, Volume 5, Leadership and Management - Politics and Governance, (pp 51-57). Oxford: Elsevier.

Sammons, P., Sylva, K., Melhuish, E. C., Siraj-Blatchford, I., Taggart, B., \& Elliot, K. (2002). The Effective Provision of Pre-School Education (EPPE) Project: Technical Paper 8a Measuring the Impact of Pre-School on Pupils' Cognitive Progress over the Pre-School Period. London: DfES / Institute of Education, University of London.

Sammons, P., Taggart, B, Smees, R, Sylva, K, Melhuish, E, Siraj-Blatchford, I \& Elliot, K (2003). The Early Years Transition and Special Needs (EYTSEN) Project, DfES Research Report RR431, London: Department for Education \& Skills.

Sammons, P., Siraj-Blatchford, I., Sylva, K., Melhuish, E., Taggart, B. and Elliot, K. (2005). Investigating the effects of pre-school provision: Using mixed methods in the EPPE 
research, International Journal of Social Research Methodology, Theory \& Practice , 8, (3), 207-224.

Sammons, P., Sylva, K., Melhuish, E., Siraj-Blatchford, I., Taggart, B. and Hunt, S. (2008a). Effective Pre-school and Primary Education 3-11 Project (EPPE 3-11): Influences on Children's Attainment and Progress in Key Stage 2: Cognitive Outcomes in Year 6. Research Report No. DCSF-RR048. Nottingham: DCSF Publications.

Sammons, P., Anders, Y., Sylva, K., Melhuish, E., Siraj-Blatchford, I., Taggart, B. and Barreau, S. (2008b), 'Children's Cognitive Attainment and Progress in English Primary Schools During Key Stage 2: Investigating the potential continuing influences of pre-school education, Zeitschrift für Erziehungswissenschaften, 10. Jahrg., Special Issue (Sonderheft) 11/2008, 179-198.

Sammons, P., Sylva, K., Melhuish, E., Siraj-Blatchford, I., Taggart, B., Toth, K., Draghici, D. and Smees, R. (2012). Effective Pre-School, Primary and Secondary Education Project (EPPSE 3-14) - Influences on students' attainment and progress in Key Stage 3: Academic outcomes in the core subjects in Year 9. London: Institute of Education, University of London I Department for Education.

Sammons, P., Hall, J, Sylva, K., Melhuish, E. , Siraj-Blatchford, I., \& Taggart, B. (2013). Protecting the development of 5-11-year-olds from the impacts of early disadvantage: the role of primary school academic effectiveness, School Effectiveness and School Improvement, 24 (2) 251-268.

Sammons, P., Sylva, K., Melhuish, E., Siraj-Blatchford, I., Taggart, B., Toth, and Smees, R. (2014a). Effective Pre-School, Primary and Secondary Education Project (EPPSE 3-14) Influences on students' GCSE attainment and progress at age 16. DfE Research Report 352, London: Institute of Education, University of London / Department for Education.

Sammons, P., Sylva, K., Melhuish, E., Siraj, I, Taggart, B., Smees, R., \& Toth, K., with Welcomme, W. (2014b). Students' views of school in Key Stage 4 age 16, London: Institute of Education \& Department of Education.

Sammons, P., Toth, K., Sylva, K., Melhuish, E., Siraj, I., \& Taggart, B. (2015). The long-term role of the home learning environment in shaping students' academic attainment in secondary school, Journal of Children's Services, 10, (3), 189-201.

Sammons, P., Toth, K. \& Sylva, K. (2015a). Subject to Background: What promotes better achievement by bright but disadvantaged students? Report for the Sutton Trust October, London: Sutton Trust. http://www.suttontrust.com/wp-content/uploads/2015/03/SUBJECTTO-BACKGROUND FULL-REPORT.pdf

Sammons, P., Toth, K. \& Sylva, K. (2015b). Background to Success: Differences in A-Level Entries by ethnicity, neighbourhood and gender, Report for the Sutton Trust October, London: Sutton Trust. http://www.suttontrust.com/wp-content/uploads/2015/11/Backgroundto-Success-Final.pdf

Sammons, P., Davis, S., \& Gray, J. (2016). Methodological and Scientific Properties of School Effectiveness Research: Exploring the underpinnings, evolution and future directions of the field, Chapter 2 in The Routledge International Handbook of Educational Effectiveness 
and Improvement: Research, policy, and practice, London: Routledge International Handbooks of Education. pp. 25-76.

Scheerens, J. (2015) Theories on educational effectiveness and ineffectiveness, School Effectiveness and School Improvement, 26(1) 10-31.

Scheerens, J. \& Bosker, R. (1997) The Foundations of educational effectiveness, Oxford: Pergamon.

Siraj-Blatchford, I., Taggart, B., Sylva, K., Sammons, P., \& Melhuish, E. (2008), Towards the transformation of practice in early childhood education: the effective provision of pre-school education (EPPE) project (2008), , Cambridge Journal of Education, Vol. 38, (1), . 23-36.

Social Mobility and Child Poverty Commission (2013). Higher Education: The Fair Access Challenge, London: Social Mobility and Child Poverty Commission. https://www.gov.uk/government/uploads/system/uploads/attachment data/file/206994/FINAL Higher Education - The Fair Access Challenge.pdf

Strand, S (2014a). "Ethnicity, gender, social class and achievement gaps at age 16: intersectionality and 'getting it' for the white working class", Research Papers in Education, 29 (2) 131-171.

Strand, S. (2014b). School effects and ethnic, gender and socio-economic gaps in educational achievement at age 11, Oxford Review of Education, 40 (2) 223-245.

The Sutton Trust $(2004 ; 2005)$. The missing 3000. State school students under-represented at leading universities. https://www.suttontrust.com/wp-content/uploads/2004/08/Missing3000-Report-2-1.pdf

The Sutton Trust (2008). Wasted talent? Attrition rates of high-achieving pupils between school and university. London: The Sutton Trust. http://www.suttontrust.com/wpcontent/uploads/2008/06/1wastedTalent.pdf

The Sutton Trust (2011). What prospects for mobility in the UK? A cross-national study of educational inequalities and their implications for future education and earnings mobility. London: The Sutton Trust http://www.suttontrust.com/wp-content/uploads/2011/11/suttontrust-crita-summary-23-11-111.pdf

Sylva, K., Siraj-Blatchford, I., \& Taggart, B. (2003). Assessing Quality in the Early Years: Early Childhood Environment Rating Scale Extension (ECERS-E): Four Curricular Subscales. Stoke on Trent, UK and Stirling, USA: Trentham Books.

Sylva, K., Siraj-Blatchford, I., Taggart, B., Sammons, P., Melhuish, E., Elliot, K., \& Totsika, V. (2006). Capturing quality in early childhood through environmental rating scales. Early Childhood Research Quarterly, 21, 76-92.

Sylva, K., Melhuish, E., Sammons, P., Siraj-Blatchford, I. and Taggart, B. (Eds) (2010). Early Childhood Matters: Evidence from the Effective Pre-school and Primary Education project. London: Routledge.

Sylva, K., Melhuish, E., Sammons, P., Siraj-Blatchford, I. \& Taggart, B. (2011). Pre-school quality and educational outcomes at age 11: low quality has little benefit, Journal of Early Childhood Research, 9 (2) 109-124. 
Sylva, K. Melhuish, E., Sammons, P., Siraj-Blatchford, I. and Taggart, B. (2014) Students' educational and developmental outcomes at age 16 EPPSE Final Report on Key Stage 4, DfE Research Report 354, London: DfE.

Taggart, B., Sammons, P., Smees, R., Sylva, K., Melhuish, E., Siraj-Blatchford, I., Elliot, K. and Lunt, I. (2006). Early identification of special needs and the definition of 'at risk': the early years transition and special education needs (EYTSEN) Project, British Journal of Special Education, 33 (1), 40-45.

Taggart, B., Siraj-Blatchford, I., Sylva, K., Melhuish, E., \& Sammons, P. (2008). Influencing policy and practice through research on early childhood education. International Journal of Early Childhood Education, 14 (2), 7-21.

Teddlie, C., Kochan, S \& Taylor D. (2002) The ABC+Model for School Diagnosis, Feedback and Improvement, in A.J. Visscher \& R. Coe (Eds.) School Improvement through

Performance Feedback (pp75-114) Lisse:Netherlands: Swets \& Zeitlinger.

Van Steensel, R. (2006). Relations between socio-cultural factors, the home literacy environment and children's literacy development in the first years of primary education, Journal of Research in Reading, 29(4), 367-382. 